\title{
CÁC VITAMIN CẦN THIẾT NHU' THẾ NÀO ĐỐI VỚI BỆNH NHÂN ĐÁI THÁO ĐƯờNG TYP 2
}

Hoàng Trung Vinh Học viện Quân y

DOI: 10.47122/vjde.2020.39.2

\section{ABSTRACT \\ The role of vitamin in type 2 diabetes patients}

The present review evaluates the relationship between type 2 diabetes mellitus and individual or combined vitamins. Antioxidant vitamins $\mathrm{A}, \mathrm{C}$ and $\mathrm{E}$ are found decreased in diabetic subjects, possibly due to an increased need to control the excessive oxidative stress produced by abnormalities in glucose metabolism. On the other hand, retinol binding protein exerts a modulating effect, as it has adipokine functions. With respect to the $\mathrm{B}$ group vitamins, thiamin, pyridoxine and biotin have been found decreased but the mechanisms are not clear, however supplementation has shown some improvement of the metabolic control in diabetic patients. The absorption of folic acid and vitamin B12 is importantly decreased by the prolongued use of metformin, which is the first choice drug in uncomplicated diabetes, thus these two nutrients have been found deficient in the disease and most probably need to be supplemented regularly. On the other hand, vitamin $\mathrm{D}$ is considered a risk factor for the development of diabetes as well as its complications, particularly cardiovascular ones. Although some studies have found an association of vitamin $\mathrm{K}$ intake with glucose metabolism further research is needed. Studies on the use of multivitamin supplements have shown unconclusive results. After reviewing the evidence, no real recommendation on the use of vitamin supplements in type 2 diabetes mellitus can be issued, however patients using metformin during prolongued periods may need folic acid and vitamin B12.

Keywords: Antioxidants, type 2 diabetes mellitus, vitamin.

\section{TÓM TẮT}

Bài tổng quan sau đây nói về mối liên quan giữa đái tháo đường typ 2 (ĐTĐT2) với từng loại vitamin nói chung cũng như vitamin tổng hợp. Nồng độ các vitamin có tác dụng chống gốc tự do như vitamin $\mathrm{A}, \mathrm{C}$ và $\mathrm{E}$ đều giảm ở $\mathrm{BN}$ ĐТĐ làm gia tăng các stress oxi hóa, góp phần gây bất thường chuyển hóa glucose. Mặt khác các protein mang retinol (vitamin $\mathrm{A}$ ) còn có tác dụng điều biển tương tự như các adipokin. Mặc dù cơ chế gây giảm nồng độ các vitamin nhóm $\mathrm{B}$ như thiamin (vitamin $\mathrm{B} 1$ ), vitamin $\mathrm{B} 6$ và biotin là hoàn toàn chưa rõ song nếu bổ sung các loại đó lại có tác dụng cải thiện kiểm soát chuyển hóa ở BN ĐTĐ. Hấp thu acid folic và vitamin B12 sẽ bị giảm đi nếu sử dụng merformin kéo dài trong khi đó đây lại là thuốc lựa chọn hàng đầu để điều trị ĐTĐ chưa có biến chứng. Chính vì vậy nồng độ hai loại này bị thiếu hụt, rất cần bổ sung thường xuyên. Vitamin $\mathrm{D}$ đóng vai trò như là yếu tố nguy cơ (YTNC) gây biến chứng ở $\mathrm{BN}$ trong đó có biến chứng tim mạch. Cũng có ý kiến cho rằng vitamin $\mathrm{K}$ có liên quan đến chuyển hóa glucose song cần phải có thêm bằng chứng trong nghiên cứu. Việc sử dụng vitamin tổng hợp cho hiệu quả chưa rõ rệt. Tuy vậy hiện nay vẫn chưa có một chỉ định thống nhất nào về bồi phụ vitamin thiếu hụt ngoại trừ sử dụng acid folic và vitamin $\mathrm{B} 12$ nếu điều trị bằng metformin kéo dài.

Tù khóa: gốc tụ do, đái tháo đường typ 2, vitamin.

Chịu trách nhiệm chính: Hoàng Trung Vinh

Ngày nhận bài: 12/2/2020

Ngày phản biện khoa học: 15/3/2020

Ngày duyệt bài: 18/4/2020

Email: hoangvinh.hvqy@gmail.com

ĐT: 0903201250 


\section{1. ĐẠT VẤN ĐỀ}

Đái tháo đường typ 2 là bệnh đa yếu tố với biểu hiện đặc trưng chuyển hóa năng lượng trong đó có carbohydrat và lipid của cơ thể, tuy vậy hầu hết các vi chất dinh dưỡng đều tham gia vào các khía cạnh khác nhau, là một trong các nguyên nhân hoặc gây ảnh hưởng đến cơ chế mạn tính. Một trong các yếu tố ảnh hưởng rõ nét lên tiến triển, biến chứng của bệnh là sự mất cân bằng giữa sự hình thành gốc tự do và việc kiểm soát các gốc tự do tự nhiên. Các vi chất dinh dưỡng có chức năng chống gốc tự do nên rất quan trọng trong tiến triển của bệnh và sự xuất hiện các biến chứng. Về khía cạnh này nhiều loại vitamin có liên quan rất chặt chẽ. Sau đây là sự điểm qua những nội dung chủ yếu về biến đổi nồng độ và vai trò của các loại vitamin ở BN ĐTĐT2.

\section{MỘT SỐ LOẠI VITAMIN CẦN THIẾT}

\subsection{Vitamin A hoặc retinol.}

Vitamin A mà dạng hoạt động chủ yếu là retinol chứa nhiều ở mô động vật trong đó có trong các acid béo. Caroten chứa nhiều trong rau quả, là một enzym thủy phân tại võng mạc mắt và chuyển thành retinol ở tế bào võng mạc. Một số santhin cũng có thể chuyển thành retinol. Vitamin $\mathrm{A}$ tham gia vào quá trình chuyển hóa đa yếu tố trong đó có sự trình diện gen, phân lập và phát triển tế bào, đóng vai trò quan trọng trong hệ thống miễn dịch, phát triển của trẻ em, thị lực, vị giác, thính giác, cảm giác ngon miệng và tạo tinh trùng. Vitamin A đóng vai trò quan trọng của chức năng chống gốc tự do, giúp ổn định nội môi trong các điều kiện thay đồi khác nhau của bệnh và stress. Vitamin $\mathrm{A}$ còn có vai trò quan trọng trong phát triển và điều hòa chức năng tuyến tụy chủ yếu ở người lớn. Vitamin A làm tăng số lượng và khối lượng tế bào $\alpha$ và $\beta$ của tuyến tụy, tăng glucose và glucagon. Nồng độ vitamin $\mathrm{A}$ cũng như protein mang retinol ở $\mathrm{BN}$ ĐTĐT2 thấp hơn so với người bình thường. Tuy vậy đa số $\mathrm{BN}$ ĐTĐT2 không cần bồi phụ vitamin $\mathrm{A}$ hóa tổng hợp mà chủ yếu bổ sung qua đường ăn uống với caroten hoặc cam thảo cũng sẽ giúp cải thiện chuyển hóa glucose ở những BN ĐTĐT2 với yếu tố nguy cơ cao [1].

\subsection{Vitamin $C$ hoặc Ascorbic acid.}

Vitamin $\mathrm{C}$ là yếu tố xúc tác của nhiều loại phản ứng khác nhau trong đó nổi bật là chống gốc tự do, tại tổ chức collagen, peptid thần kinh và tổng hợp carnitin, giúp tăng hấp thu sắt, ức chế giải phóng histamin và kích thích hệ miễn dịch. Nồng độ vitamin $\mathrm{C}$ thấp ở $\mathrm{BN}$ ĐTĐT2 so với người bình thường. Nồng độ vitamin $\mathrm{C}$ trong huyết tương tương quan nghịch với $\mathrm{HbA1c}$, nồng độ glucose máu lúc đói và sau ăn cũng như stress oxi hóa. Nếu nồng độ vitamin $\mathrm{C}$ huyết tương cao và ăn nhiều hoa quả sẽ giảm được một số YTNC tiến triển của ĐTĐT2. Bổ sung vitamin $\mathrm{C}$ không chỉ cải thiện chuyển hóa glucose mà còn cả huyết áp, lipid và các sản phẩm của urê. Nghiên cứu cho thấy $50 \% \mathrm{BN}$ với bệnh võng mạc do ĐTĐ đều có giảm nồng độ vitamin C [2].

\subsection{Vitamin E.}

Vitamin E là một trong các loại vitamin có tác dụng chống gốc tự do rất quan trọng, bảo vệ sự trọn vẹn của màng tế bào bằng cách ức chế tác dụng của các lipid với bản chất gốc tự do. Vitamin $\mathrm{E}$ có tác dụng dự phòng xuất hiện bệnh ĐTĐT2. Nếu nồng độ vitamin E huyết tương thấp dưới mức bình thường sẽ làm gia tăng 3,9 lần nguy cơ liên quan với ĐTĐ. Bệnh nhân ĐTĐ thường có nồng độ vitamin $\mathrm{E}$ huyết thanh thấp hơn so với người khỏe mạnh. Nếu bổ sung vitamin E bị thiếu hụt sẽ giúp cải thiện độ nhạy cảm insulin ở đối tượng dư cân, tuy vậy đây không phải là hiệu quả có lợi khi bổ sung vitamin $\mathrm{E}$ trong việc kiểm soát glucose ở BN ĐTĐT2. Bổ sung vitamin $\mathrm{E}$ có thể làm giảm $\mathrm{HbA} \mathrm{c} c$ ở $\mathrm{BN}$ kiểm soát glucose chưa tương thích khi đối tượng đó có giảm nồng độ vitamin E. Nghiên cứu thuần tập cho thấy nếu bổ sung vitamin $\mathrm{E}$ liều cao ( $\geq 400 \mathrm{IU} /$ ngày) có thể hạn chế được tử vong do nhiều nguyên nhân [1].

\subsection{Thiamin hoặc vitamin B1}

\subsection{Tỷ lệ biến đổi nồng độ thiamin ở} bệnh nhân đái tháo đường.

Tùy thuộc vào đối tượng nghiên cứu các tác giả đã đưa ra một số nhận xét khác nhau 
về biến đổi nồng độ thiamin ở BN ĐTĐ. Esther $\mathrm{G}$ và cs năm 2014 cho thấy $\mathrm{BN}$ ĐTĐ typ 1 và 2 có tỷ lệ thiếu thiamin từ $17 \%$ đến 79\% [7]. Roxana V và cs năm 2015 lại nhận thấy tỷ lệ giảm thiamin dao động từ $64 \%$ đến $75 \%$ đối với cả hai typ ĐТĐ [1]. Nồng độ các loại vitamin nhóm $\mathrm{B}$ trong đó có thiamin trong huyết tương đều giảm ở BN ĐTĐT2 so với nhóm chứng, theo đó ở BN ĐTĐT2 nồng độ trung bình là $22,7 \mathrm{nmol} / 1$; ĐTĐT2 với microalbumin niệu $(+)$ là $26,8 \mathrm{nmol} / 1$; ĐTĐ không có microalbumin niệu là $39,5 \mathrm{nmol} / 1$. Tỷ lệ giảm thiamin $(<30 \mathrm{nmol} / 1)$ ở các đối tượng trên tương ứng $63 \% ; 58 \%$ và $25 \%$ [4]. Pácal $\mathrm{L}$ và cs năm 2014 cho thấy $75 \% \mathrm{BN}$ ĐTĐ có giảm nồng độ thiamin so với người khỏe mạnh [5]. Page $J$ và cs 2011 cũng nêu ra kết quả tương tự: tỷ lệ $\mathrm{BN}$ ĐTĐT2 có giảm thiamin gặp $17-79 \%$, liên quan đến tăng glucose máu, rối loạn chức năng nội mạc, stress oxi hóa, tổn thương mạch máu nhỏ nhất là mạch máu thận [6]. Theo Diabetes care 2018 thì có khoảng 36-47\% thiếu hụt vitamin B1 ở những đối tượng tăng glucose máu bao gồm có carbohydrat cao, đái tháo đường, phụ nữ mang thai. Trên thực nhiệm thiếu thiamin dẫn đến giảm tổng hợp insulin. Thiamin có tác dụng cải thiện chức năng nội mạc mạch máu, giảm sự xuất hiện bệnh tim mạch, cải thiện rối loạn lipid máu. Sử dụng thiamin liều cao có tác dụng giảm albumin niệu tới $34 \%$ ở BN ĐTĐT2, cải thiện triệu chứng của bệnh thần kinh ngoại vi, bệnh võng mạc. Ngược lại tăng glucose máu dấn đến gia tăng biểu hiện đột biến tế bào lympho dẫn đến nguy cơ xuất hiện ung thư. Dùng thiamin liều cao ở $\mathrm{BN}$ ĐTĐ có tác dụng làm hạn chế biến đổi gen và sau đó là hạn chế xuất hiện bệnh ung thư [7]. Thornalley $\mathrm{P}$ và cs năm 2007 cho thấy ở $\mathrm{BN}$ ĐTĐT1 có $76 \%$ trường hợp giảm nồng độ thiamin; 75\% ở bệnh nhân ĐTĐT2, tương ứng với $15,3 \mathrm{nmol} / 1$ và $16,3 \mathrm{nmol} / 1$ so với $64,1 \mathrm{nmol} / 1$ ở người khỏe mạnh. Giảm thiamin ở bệnh nhân ĐTĐ chủ yếu là do tăng lọc thiamin qua thận và rõ nét nhất là thiamin vận chuyển chứa trong hồng cầu bị mất qua nước tiểu [8].

\subsubsection{Nguyên nhân giảm thiamin ở bệnh} nhân đái tháo đưòng

Tồn tại một số nguyên nhân làm giảm nồng độ thiamin ở BN ĐTĐ. Nhiều tác giả cho rằng nguyên nhân chủ yếu giảm thiamin là do tăng lọc thiamin qua thận mà rõ nét nhất là thiamin vận chuyển chứa trong hồng cầu bị mất trong nước tiểu. Nồng độ thiamin huyết tương tương quan nghịch với độ thanh thải thiamin của thận và phân số thải của thiamin [8]. Rabbani $\mathrm{N}$ và cs năm 2008 cũng cho rằng nồng độ thiamin giảm ở BN ĐTĐ chủ yếu liên quan đến tăng thải thiamin và tác động đối nghịch của tăng glucose máu [9]. Nồng độ thiamin có thể giảm nhất là khi sử dụng quá nhiều carbohydrat cũng như khi có biến chứng của thần kinh ngoại vi [10]. Tăng glucose máu cũng sẽ dẫn đến thiếu hụt thiamin ảnh hưởng đến chuyển hóa glucose trong tế bào do giảm hoạt tính enzym transketolase. Nồng độ thiamin giảm dần khi bệnh nhân có biến chứng thận nặng dần [11].

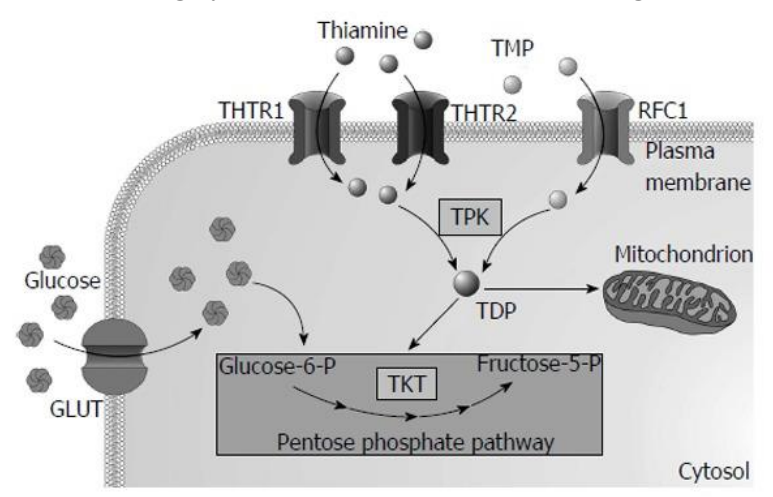

Hình 4.1. Sơ đồ chuyển hóa thiamin trong tế bào [14] 
GLUT: Glucose transporter; THTR1: Thiamine transporter 1; THTR2: Thiamine transporter 2; TKT:Transketolase; TPK: Thiamine pyrophosphokinase; RFC1: Reduced folate carrier 1; TDP: Thiamine diphosphate.

Một trong các cơ chế sinh hóa cả ĐTĐ gây tăng glucose máu là con đường polyol, trong đó có sự tham gia của các enzym như aldose reductase, tramsform D - glucose sorbitol dẫn đến mất sự cân bằng nội môi trong tế bào. Bên cạnh đó thiamin, benfotiamin cũng tham gia vào con đường polyol, hoạt hóa transketolase, chuyển hóa glucose trong tế bào nội mạc mạch máu và cả tế bào ngoại mạc khi môi trường tăng glucose.

Ở BN ĐTĐ nhận thấy giảm nồng độ thiamin. Nếu bổ sung thiamin sẽ có tác dụng dự phòng tổn thương tế bào do tăng glucose máu gây ra, giúp hoạt hóa glyceraldehyde -3 phosphate $(\mathrm{G} 3 \mathrm{P})$ và tạo điều kiện sử dụng tốt acetyl - CoA được sinh ra từ tình trạng tăng thủy phân glucose [12]. Thiamin và benfotiamin có tác dụng điều chỉnh các phần tử proteinase gian bào xuất hiện do tăng glucose ở tế bào ngoại mạch võng mạc trong khi đó lại có tác dụng tăng ức chế tế bào phần tử proteinase 1 [13].

\subsubsection{Hậu quả giảm thiamin ở bệnh nhân đái tháo đường.}

Thiamin đóng vai trò như một chất xúc tác của các phản ứng trong đó có chuyển hóa glucose nội bào. Giảm nồng độ thiamin ở $\mathrm{BN}$ ĐTĐT2 dẫn đến hoạt hóa proteinkinase $\mathrm{C}$ đóng vai trò trong việc xuất hiện bệnh nội mạc mạch máu do ĐTĐ kể cả mạch máu nhỏ và mạch máu lớn, rối loạn lipid, biến chứng mắt, thận, tim và thần kinh [15]. Thiếu hụt thiamin dần đến giảm tổng hợp và tiết insulin gây thiếu hụt insulin nội sinh [3]. Thiếu hụt thiamin là nguyên nhân gây giảm thủy phân glucose. Dù tăng hay giảm thủy phân glucose đều liên quan đến nồng độ thiamin trong máu. Nồng độ glucose tương quan nghịch với nồng độ thiamin [16].

Nồng độ thiamin đóng vai trò quan trọng trong chuyển hóa ở tế bào [17]. Đột biến gen vận chuyển thiamin SLC19A2 có thể dẫn đến sự xuất hiện ĐTĐ đơn gen, thiếu máu và điếc dẫn truyền.

Sau khi bổ sung vitamin B1 sẽ cải thiện rõ các đáp ứng về rối loạn huyết học và kiểm soát glucose máu nhưng không làm thay đổi điếc [18]. Thiếu hụt thiamin ở $\mathrm{BN}$ ĐTĐ ảnh hưởng đến chuyển hóa glucose máu mạn tính. Một nghiên cứu tiến hành ở $60 \mathrm{BN}$ ĐTĐT2 và 26 đối tượng thuộc nhóm chứng được bổ sung $100 \mathrm{mg}$ vitamin $\mathrm{B} 1 /$ ngày trong 6 tháng. Chỉ sau 3 tháng nhận thấy tất cả đều giảm cholesterol toàn phần. Ở BN ĐTĐ ngoài giảm cholesterol toàn phần còn có tác dụng giảm LDL-c.

Tác giả kết luận: như vậy vitamin B1 có tác dụng dự phòng biến chứng của ĐTĐ nếu sử dụng lâu dài [19]. Giảm thiamin ở BN ĐTĐ liên quan đến tăng glucose máu, rối loạn chức năng nội mạc mạch máu và stress oxi hóa, tổn thương mạch máu nhỏ nhất là mạch máu thận [6]. Nồng độ thiamin giảm dần khi xuất hiện biến chứng thận tăng dần [20]. Thiamin là một enzym xúc tác và cần thiết cho chuyển hóa glucose trong tế bào.

Con đường hóa sinh tổng hợp hexosamine sinh ra tín hiệu liên quan đến xơ hóa tế bào thận và cơ tim. Nếu bổ sung vitamin $\mathrm{B} 1$ đầy đủ sẽ có tác dụng dự phòng xơ hóa tế bào cơ tim ở $\mathrm{BN}$ ĐTĐ bằng cách ức chế con đường hóa sinh tổng hợp hexosamine [3]. Quá trình tích tụ triosephosphate gia tăng khi tăng glucose máu gây rối loạn các phản ứng hóa sinh dẫn đến tổn thương thận ở BN ĐTĐ.

Nếu sử dụng thiamin hoặc benfotiamin liều cao có tác dụng giảm sự tích tụ triosephosphate dẫn đến ức chế quá trình tổn thương thận ở giai đoạn sớm. Thiamin sử dụng liều cao làm gia tăng trình diện transketolase ở cầu thận, tăng chuyển hóa dạng triosephophate thành ribose - 5 phosphate và ức chế mạnh mẽ sự xuất hiện cũng như tiến triển của albumin niệu, ngoài ra còn liên quan đến giảm hoạt tính của proteinkinase $\mathrm{C}$, giảm glycat hóa protein và stress oxi hóa. Đây là 3 cơ chế rối loạn hóa sinh chủ yếu khi tăng glucose máu. Benfotiamin có tác dụng ức chế cường chức năng lọc của cầu thận được sinh ra ở $\mathrm{BN}$ ĐTĐ [21]. 


\subsection{Niacin hoăc vitamin $B 3$}

Niacin hoặc nicotinic acid thuộc thành phần của nicotinamide ademine dinucleoticde (NAD) và NADH là adenosine triphosphate (ATP) tự nhiên có vai trò sản sinh năng lượng ở mức tế bào. Niacin liều cao sử dụng để điều trị rối loạn lipid máu có tác dụng tăng HDL-c, giảm cholesterol, triglycerid. Thông thường niacin được sử dụng phối hợp với các thuốc điều trị rối loạn lipid như statin. Tuy vậy nghiên cứu hồi cứu cho thấy bổ sung niacin có thể làm gia tăng bệnh ĐTĐT2 mới chẩn đoán song lại có tác dụng giảm nguy cơ biến chứng tim mạch độc lập với mức glucose nền. Một nghiên cứu kéo dài 3 năm với việc sử dụng niacin cho những đối tượng có glucose máu nền bình thường đã gây tăng glucose máu và nguy cơ tăng glucose máu lúc đói song chưa xuất hiện bệnh đái tháo đường [2].

\subsection{Pyridoxine hoặc vitamin B6.}

Pyridoxine tác dụng như một coenzym của quá trình phosphoryl hóa glucose, rất cần thiết cho quá trình huy động glycogen ở gan và co, đóng vai trò quan trọng trong chuyển hóa glucose. Bệnh nhân ĐTĐT2 thường có giảm pyridoxal $-5^{\prime}-$ phosphate (PLP). Đây là dạng hoạt động của vitamin B6, đặc biệt thiếu hụt nồng độ vitamin $\mathrm{B} 6$ thể hiện rất rõ ở $\mathrm{BN}$ ĐTĐT2 có microalbumin niệu (MAU). Tuy vậy bổ sung vitamin B6 lâu dài kết hợp với acid folic và vitamin $\mathrm{B} 12$ không có tác dụng làm giảm sự xuất hiện bệnh ĐTĐ. Nếu phối hợp vitamin $\mathrm{B} 6$ với vitamin $\mathrm{B} 1$ thì sẽ giảm quá trình glycat hóa DNA trong tế bào bạch cầu ở BN ĐTĐ. Trên thực nghiệm bổ sung pyridoxine làm tăng độ nhạy insulin và giảm nồng độ insulin song không gây biến đổi nồng độ glucose. Mặc dù vậy thiếu vitamin B6 không được cho là yếu tố gây bệnh thần kinh ngoại vi ở BN ĐTĐ và điều trị bệnh thần kinh ngoại vi với vitamin B6 liều cao cho kết quả cải thiện triệu chứng chỉ tương tự như nhóm placebo không sử dụng vitamin B6. Bổ sung vitamin $\mathrm{B} 6$, folate và vitamin $\mathrm{B} 12$ trong một thử nghiệm 6 tháng giúp giảm được phù nề đáy mắt, làm tăng thị lực của $\mathrm{BN}$ với bệnh võng mạc không tăng sinh [1].

\subsection{Folate, folic acid hoăc vitamin B9.}

Folate là thành phần tự nhiên để tổng hợp DNA và một chất xúc tác quan trọng trong chuyển hóa aminoacid nói chung và homocystein (Hcy) thành methionin nói riêng. Cũng tương tự như thiếu hụt vitamin B12 thì thiếu hụt folate sẽ gây tăng Hcy - yếu tố nguy cơ biến chứng tim mạch. Nếu bố sung folic acid hoặc vitamin nhóm $\mathrm{B}$ ở $\mathrm{BN}$ có YTNC cao sẽ giảm được nồng độ Hcy song không có tác dụng làm chậm tiến triển của bệnh ĐTĐT2. Nồng độ folate huyết tương ở BN ĐTĐT2 mới chẩn đoán hoặc chẩn đoán từ trước cao hơn có ý nghĩa so với đối tượng có dung nạp glucose máu bình thường. Cũng tương tự như vitamin $\mathrm{B} 12$ thì metformin làm giảm nồng độ folate. Bổ sung folic acid ở $\mathrm{BN}$ nam ĐTÐ có sử dụng metformin sẽ có tác dụng cải thiện nồng độ Hcy và khả năng chống gốc tự do. Kết quả nghiên cứu thuần tập cho thấy bổ sung folic acid có tác dụng giảm Hcy, cải thiện kiểm soát ĐTĐ. Folate đóng vai trò trong xuất hiện và tiến triển bệnh võng mạc ĐTĐ, có ảnh hưởng (+) lên triệu chứng và dấu hiệu của bệnh võng mạc ĐTĐ nếu đồng thời bổ sung cả vitamin $\mathrm{B} 6$, folate và vitamin $\mathrm{B} 12$. Phụ nữ với đái tháo đường thai kỳ có thể sử dụng $5 \mathrm{mg}$ folic acid trước khi mang thai và 12 tuần đầu tiên sau khi có thai với tác dụng dự phòng khiếm khuyết ống thần kinh của thai nhi [2].

\subsection{Biotin}

Tác dụng của biotin như một chất xúc tác quá trình tổng hợp và kéo dài của các acid béo, pyruvate carboxylase thuộc CoA. Nồng độ biotin giảm ở BN ĐTĐT2 so với người khỏe mạnh, tương quan nghịch với nồng độ glucose máu lúc đói. Nếu uống biotin $9 \mathrm{mg} / \mathrm{ngày}$ có thể giúp điều chỉnh tăng glucose máu song không gây biến đổi nồng độ insulin. Việc nghiên cứu mối liên quan giữa biotin và ĐTĐT2 vẫn còn ít [1].

\subsection{Cobalamin hay vitamin B12.}

Vitamin B12 là chất xúc tác trong quá trình methyl hóa từ Hcy thành methionin, chính vì vậy đóng vai trò tự nhiên đối với hệ thần kinh và gan. Thiếu vitamin $\mathrm{B} 12$ dẫn đến tăng $\mathrm{Hcy}-$ đây là yếu tố nguy cơ độc lập đối với vữa xơ 
động mạch. Vitamin B12 cần thiết cho quá trình tổng hợp DNA và một số chất dẫn truyền thần kinh như serotonin và dopamin. Thiếu hụt vitamin $\mathrm{B} 12$ dẫn đến tổn thương thần kinh với biểu hiện bệnh thần kinh ngoại vi và thần kinh tự động mức độ nặng, gây thoái hóa tủy sống, suy giảm trí nhớ. Tỷ lệ thiếu vitamin B12 ở BN ĐTĐT2 gia tăng. Metformin gây thiếu hụt vitamin B12 ở BN ĐTĐT2 song kể cả bệnh nhân không sử dụng metformin vẫn có biểu hiện thiếu hụt vitamin B12.

Bệnh thần kinh ngoại vi gây ra do bệnh ĐTĐ và thiếu vitamin $\mathrm{B} 12$ có thể che lấp các triệu chứng lâm sàng của bệnh. Bệnh thần kinh không do ĐTĐ cũng có thể xuất hiện ở $\mathrm{BN}$ ĐTĐ và cũng cần được điều trị. Nhìn chung sử dụng vitamin B12 kết hợp với các loại vitamin nhóm $\mathrm{B}$ sẽ có tác dụng cải thiện triệu chứng của bệnh thần kinh ngoại vi do ĐTĐ [2].

\subsection{Vitamin D}

Vitamin $\mathrm{D}$ đóng vai trò trong chuyển hóa xương và điều hòa hấp thu canxi, phospho ở tổ chức kẽ. Thiếu hụt vitamin $\mathrm{D}$ ảnh hưởng bất lợi lên chuyển hóa glucose, giảm chức năng tế bào $\beta$ tụy, tăng kháng insulin và dung nạp glucose. Có mối liên quan ngược giữa nồng độ vitamin $\mathrm{D}$ và nguy cơ xuất hiện ĐTĐT2. Nồng độ vitamin $\mathrm{D}$ giảm ở $\mathrm{BN}$ ĐTĐT2 so với người khỏe mạnh. Bổ sung vitamin $\mathrm{D}$ giúp giảm kháng insulin và nồng độ insulin lúc đói song không ảnh hưởng đối với glucose máu lúc đói và $\mathrm{HbA1c}$. Nếu sử dụng vitamin $\mathrm{D}$ liều cao đường tiêm bắp sẽ có tác dụng giảm triệu chứng đau của bệnh thần kinh ngoại biên do ĐТÐ [2].

\section{KẾT LUẬN}

Tuy có biến đổi rõ rệt mà đa phần là giảm nồng độ nhiều loại vitamin ở BN ĐTĐ. Sự thiếu hụt các loại vitamin đã ảnh hưởng lên tiến triển, diễn biến của bệnh song hiện nay chưa có một chỉ định, khuyến cáo cụ thể nào để bồi phụ sự thiếu hụt các loại vitamin ở $\mathrm{BN}$ ĐTĐ ngoại trừ cần bổ sung vitamin $\mathrm{B} 12$ ở $\mathrm{BN}$ sử dụng metformin lâu dài. Cần thiết phải xác định biểu hiện và mức độ thiếu hụt từng loại vitamin nhất là vitamin $\mathrm{B} 1$ để có biện pháp bồi phụ. Đây là các biểu hiện và biện pháp điều chỉnh mang tính cá thể hóa. Sử dụng các thuốc chống gốc tự do lâu dài cũng chưa được nêu trong khuyến cáo. Bồi phụ sự thiếu hụt các loại vitamin bằng con đường ăn uống vẫn là thích hợp nhất và cần được chú ý.

\section{TÀI LIÊU THAM KHẢO}

1. Hasan K, Aminul I, Moinul I, et al. (2017)"Vitamins and Type 2 Diabetes Mellitus". JCD, 4(1), pp.3-9.

2. Roxana V, Laura L, Elina $M$, et al.(2015)"Vitamins and type 2 Diabetes Mellitus". Endocr Metab Immune Disord Drug Targets, 15(1), pp/54-63.

3. Esther G, Nanne K (2014). "Thiamine Management", Diapedia the living textbook of diabetes, no 8,pp.1/4-4/4.

4. Nix A, Zirwes $R$, Bangert $V$, et al. (2014)."Vitamin B status in patients with type 2 diabetes mellitus with and without incipient nephropathy". Diabetes Research and Clinical Practice, pp.157165.

5. Pácal L, Kuricová K, KanKová, et al. (2014) "Evidence for altered thiamine metabolism in diabets: Is there a potential to oppose gluco - and lipotoxicity by rational supplementation?". World J Diabetes, 5(3), pp. 288-295.

6. Page J, Laight, Cummings H (2011). "Thiamine deficiency in diabetes mellitus and the impact of thiamine replacement on glucose metabolism and vascular disease". Int J Clin Pract, 65(6), pp. 684-690.

7. Introduction: Standards of Medical Care in Diabetes (2018)."Introduction: Standards of medical care in diabetes 2018". Diabetes Care 2018; 41(1). pp s1s10.

8. Thornalley P, Babaei - Jadidi R, Ali A, et al. (2007)"High prevalence of low plasma thimine concentration in diabetes linked to a marker of vascular disease". Diabetes and Endocrinology. 
9. Rabbani N, Thornalley P (2008)."Emerging role of thiamine therapy for prevention and treatment of earlys stage diabetic nephropathy". Diabetes, obesity and metabolism.

10. Baltramo E, Berrone E, Tarallo S, et al. (2008)"Effects of thiamine and benfotiamine on intracellular glucose matabolism and relevance in the prevention of diabetic complications". Acta Diabetol, pp.131-141.

11. Pácal L, Tomandl J, Jan $\mathrm{S}$, et al. (2011)"Role of thiamine status and genetic variability in transketolase and other pentose phosphate cycle enzymes in the progression of diabetic nephropathy". Nephrol Dial Transplant, pp.1229-1236.

12. Berrone E, Beltramo E, Solimine C, et al. (2006) "Regulation of intracellular Glucose and Polyol Pathway by Thiamine and Benfotiamine in High Glucose". The Journal of Biological Chemistry, 281(14), pp.9307-9313.

13. Tarallo S, Beltramo E, Berrone, et al. (2009) " Effects of high glucose and thiamine on the balance between matrix metalloproteinases and their tissue inhibitors in vascular cells". Acta Diabetol 47, pp. 105-111.

14. Khanh Vinh Quoc Luong, Lan Thi Hoang Nguyen (2012). "The Impact of Thiamine treatment in the Diabetes Mellitus". Journal of Clinical Medicine Research, 4(3), pp. 153-160.

15. Hobara R, Ozawa K, Okazaki M, et al. (1981) "Ralationship between thiamine and glucose levels in diabetes mellitus". Japan J Pharmacol, pp.1098-1100.

16. Alam S, Riaz $S$, Akhtar $M$, et al. (2012)"Effect of High Dose Thiamine Therapy on Risk Factors in Type 2 Diabetes". Journal of Diabetes \& Metabolism, pp.1/15-15/15.

17. Ali S, Baitei $\mathrm{E}$, Zou $\mathrm{M}$, et al. (2006)"Thiamine transporter mutation: an example of monogenic diabetes mellitus". European Journal of Endocrinology, pp.787-792.

18. Omar A, Nasser A, Alokail M, et al. (2014)"Metabolic benefits of Six month Thiamine supplementation in Patiens with and without Diabetes Mellitus Type 2". Clinical Medicine Insights: Endocrinology and Diabetes, pp.1/3-3/3.

19. Pácal L, Tomandl J, Jan $\mathrm{S}$, et al. (2011)"Role of thiamine status and genetic variability in transketolase and other pentose phosphate cycle enzymes in the progression of diabetic nephropathy". Nephrol Dial Transplant, pp.1229-1236.

20. Yuka K, Shirakawa H, Yamane K, et al. (2008). "Prevention of incipient diabetic cardiomyopathy by high-dose thiamine". The Journal of Toxicological Sciences (J.Toxicol. Sci), 33(4), pp.459-472.

21. Roya B, Nikolaos K, Ahmed N, et al. (2003)"Prevention of Incipient Diabetic nephropathy by High - Dose Thiamine and Benfotiamine". Diabetes 52, pp.2110-2120. 